\title{
A Descriptive Epidemiological Study of Snake Bite Cases Among Children in Eastern Nepal
}

\author{
Nirjala Aryal, , Moon Thapa, Umesh Singh and Manju Shrestha
}

Department of Paediatrics, Nepalese Army Institute of Health Sciences, Shree Birendra Hospital, Chhauni, Kathmandu, Nepal
ABSTRACT
Introduction: Snake bite is a significant health issue globally. In Nepal, WHO has estimated more than 20,000 snake bites occurring annually. The prevalence of snake bite in children in Nepal has not been specified yet due to relatively few researches. This study explores the epidemiological data on snake bite among children below 18 years of age from a snake bite treatment center located at Itahari in the eastern part of Nepal.

Methods: This is a descriptive study of the secondary data from treatment records of snake bites among children up to 18 years of age in Samudayek Sarpadansa Upachar Kendra, Itahari, Nepal. The center is located in Army Camp in the eastern plains of Nepal and provides treatment services to all snake bite victims. Recorded data of the patients brought in for treatment in the treatment center from October 2015 to October 2016 were segregated for age group 0 to 18 years and analyzed.

Results: Among 395 cases of snake bite in children below 18 years of age, 57\% were boys and most were between 11-15 years. The peak season of bite was during monsoon with clustering of $44 \%$ cases from 6 PM to $12 \mathrm{AM}$ and lower limb was the most common site of bite. A total of $7.1 \%$ of snake bite cases needed treatment with anti-snake venom.

Conclusion: Snake bite among children below 18 years of age is more common among boys, especially during monsoon and evenings. Only small portion of snake bites require treatment with anti-snake venom.

Keywords: children; envenoming; snake bite; anti-snake venom; neurotoxic
\end{abstract}

Correspondence: Nirjala Aryal, Department of Paediatrics, Nepalese Army Institute of Health Sciences, Shree Birendra Hospital. Email: nirjalaaryal@gmail.com

To cite this article: Aryal N, Thapa M, Singh U, Shrestha M. A Descriptive Epidemiological Study of Snake Bite Cases Among Children in Eastern Nepal. Medical Journal of Shree Birendra Hospital. 2017;17(2):10-7.

\section{DOI: $\underline{\text { http://dx.doi.org/10.3126/mjsbh.v16i2.18471 }}$}

\section{Conflict of Interest: None declared}




\section{INTRODUCTION}

Snakebite represents a significant health issue worldwide. Among 3,500 species of snakes identified in the world 500 are poisonous. ${ }^{1}$ Out of 250 species of snakes found in South East Asia, only 60 species are known to be poisonous. In Nepal, out of 77 species of identified snakes, 21 are poisonous, and distribution is largely dependent up on geography and climate. 2,3

Around four million snake bites occur annually in Asia, of which $50 \%$ are poisonous resulting in 100,000 deaths every year. ${ }^{4}$ A high incidence of snake bite envenomation is seen in Terai region of Nepal which is the plain fertile land of the southern region of the country. However, there is lack of epidemiological data nationwide. WHO reports more than 20,000 snake bites annually resulting in 1,000 deaths. ${ }^{5}$ In Nepal, the prevalence of snake bite in children is relatively unknown as limited studies have been conducted. Various studies in different countries in Asia have reported variable results. The prevalence of snake bites in a study done in Kangar district Malaysia were 7\% and 33\% in children among 0-9 years and 10-19 years respectively. ${ }^{6}$ In India snake bite accounted for 3\% of all deaths in children aged between 5-14 years. ${ }^{7}$

The Zoonotic Disease Control Section of the Department of Health Services of Nepal conducted an epidemiological study in 12 districts of Terai in the year 1984/85. The study was focused on snakebite, its treatment and management. ${ }^{8}$ In this study, several varieties of highly venomous species of snakes were found. Among poisonous snakes four species of Krait e. g. Bungarus caeruleus (Common Indian Krait), Bungarus fasciatus (Banded Krait) and three species of Cobra eg. Naja Naja (Common Cobra), Ophiophagus Hannah (King Cobra) were reported in Nepal. Other species include 11 species of green pit vipers, one species each of Mountain pit Viper, Agkistrodon himalayanus (Himalayan Pit Viper) and Daboia russelii (Russell's Viper). ${ }^{3,9}$ Among the venomous species Viperidae (Viper) and Elapidae (Cobra and Krait) families are found to be responsible for the highest number of bites and mortality. ${ }^{10}$ Family Elapidae is the most common poisonous snake found in Terai of Nepal causing annual morbidity of $162 / 100,000$ individuals. ${ }^{5}$

Envenomation by Viperid snakes result more in hematological disturbances like hemorrhage from various sites including recent wound and fang marks. They also induce prominent local signs (edema, blistering and necrosis), cardiovascular shock, and acute renal failure. Neurological involvement like increase salivation, ptosis, respiratory and generalized paralysis are seen more with Elapidae bite. ${ }^{3}$

The objectives of this study were to find out the epidemiology of snake bites in children and look into the morbidity and mortality of snake bites in children less than 18 years of age living in the eastern plains of Nepal.

\section{METHODS}

The study is descriptive in nature analyzing the secondary data of snake bite in children aged up to 18 years in the Samudayek Sarpadansa Upachar Kendra, Itahari, Nepal. The center is located in Army Camp in Eastern Nepal and provides treatment services to all snake bite victims accessing service. It has observation and emergency rooms equipped with cardiac monitor and equipment required for cardiopulmonary resuscitation. The treatment center provides First Aid treatment as well as the anti-snake venom for indicated patients according to the National Guidelines 2013. As the treatment center doesn't have ICU facility, patients with medical complications needing cardiopulmonary support are referred to nearby higher treatment centers. The First Aid treatment and anti-snake venom (ASV) 
treatment depending on the clinical features are provided by medical and paramedical staffs of Nepalese Army in treatment center.

The name, age, sex and address of the patient, identification of the snake, treatment given and outcome (improved, referred or death) of patient were recorded in a record book. Recorded data of the patients brought in for treatment in the center for a period of 13 months from October 2015 to October 2016 were included in the study.

The snake bite victims were evaluated based on the history, inspection of the bite wound and clinical examination for signs of poisoning. The observations and examination findings were documented and patients were admitted in observation ward for 12 hours. Based on the presence and absence of signs and symptoms of envenomation, patients were either treated with anti-snake venom (ASV) or discharged after 12 hours.

Following the National Guideline 2013, ASV was given to those developing signs of systemic envenomation producing neurotoxicity (e.g. external ophthalmoplegia, ptosis, respiratory paralysis), hemodynamic instability (hypotension

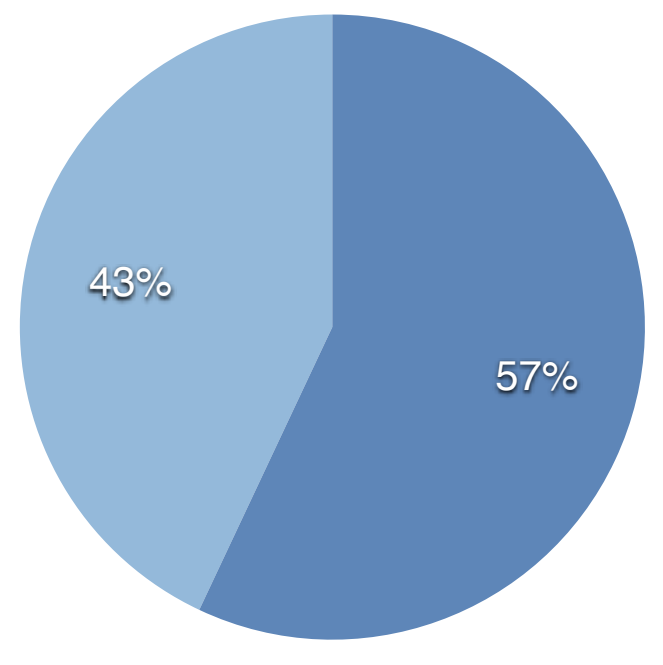

Male

Female

Figure 1: Sex wise distribution of snakebite patients $(n=395)$ or shock), acute renal failure (oliguria or anuria), spontaneous bleeding as manifestation of hemotoxic poisoning and the signs of local envenoming as observed by rapidly spreading swelling of the bitten limb or swelling extending more than half of the bitten limp, not due to the tourniquet or enlarged tender lymph nodes draining the bitten limb. ${ }^{3}$

Out of total recorded cases during the study period, data were filtered for age group 0 to 18 years, entered in Microsoft Excel 2007 and analyzed.

\section{RESULTS}

There were total 1646 cases of snake bite during the study period. Among those, 395 cases of snake bite occurred in children aged less than 18 years. This was $24 \%$ of the total snake bite cases recorded and among them 227 were boys and 172 girls (Fig. 1).

The maximum number of snake bites $(n=187)$ were between the age group of 1 1- 15 years followed by 16 - 18 years (Fig. 2). Lesser number of snake bite victims was seen in younger age group. There were only 5 cases aged below 5 years.

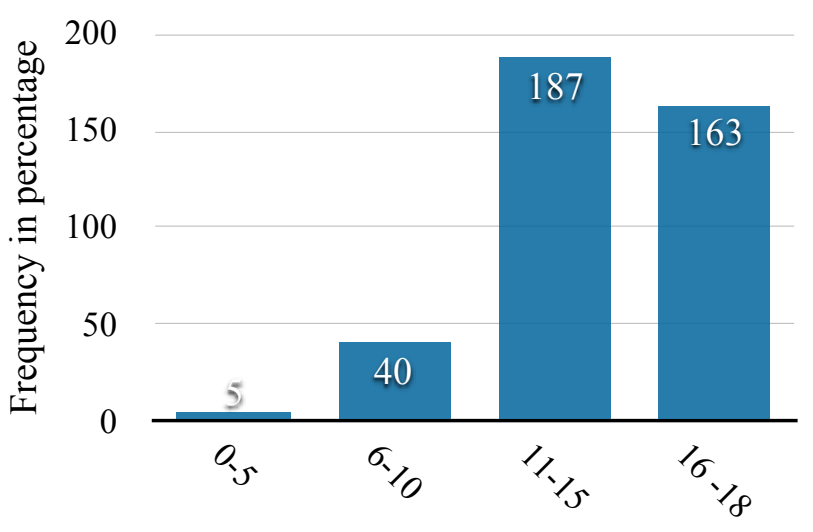

Age group in years

Figure 2: Age distribution of snake bite patients $(\mathrm{n}=395)$ 
Table 1: Distribution of patients according to site of bite and type of snake

\begin{tabular}{|c|c|c|c|}
\hline Site of bite & Number of cases & Type of snake & Number of cases \\
\hline Lower extremities & 269 & Cobra & 21 \\
\hline Upper extremities & 118 & Green pit viper & 11 \\
\hline Neck and face & 3 & Krait & 10 \\
\hline Back & 2 & Mountain pit viper & 4 \\
\hline Others & 3 & Unknown & 349 \\
\hline
\end{tabular}

Majority of the patients brought to the treatment center were from surrounding districts - Sunsari, Morang and Saptari. Very few cases were from other districts - Rupandehi, Sankhuwasava and Dhankuta (Fig. 3).

Seasonal variation of the snake bite showed that majority of the cases brought for treatment were during monsoon peaking at the month of June and July. Only few cases were seen during winter months of December and January (Fig. 4)

Though snake bite was seen throughout the day, maximum number $(\mathrm{N}=173)$ occurred during the night, from $6 \mathrm{PM}$ to $12 \mathrm{AM}$. Snake bite from mid night to $6 \mathrm{AM}(\mathrm{N}=43)$ was the lowest (Fig 5).

The bite was most common in lower extremities $(68.9 \%)$ and in upper extremities $(29.9 \%)$. There were very few cases of bites on other parts of the body. In $88 \%$ cases, the victims as well as the observers were not sure about the species of snake.
Out of identified snakes' species, the majority were Cobra followed by Green Pit Viper and Krait (Table 2). The identification of snakes was done either by looking at the dead snakes brought along with the patient or as described by the observers or the victims. Out of total 395 cases of suspected snake bite cases admitted in the treatment center only $7.1 \%(\mathrm{~N}=28)$ were envenomed needing treatment with ASV. Among these, 15 were Cobra bites and 8 were Krait bite. None of the Viper bites from known category needed treatment with ASV. Total of 5 cases with unknown category required ASV treatment which might have included Viper bite. Among the envenomed victims, one with Krait bite died during the treatment and four were referred to other centers with ICU setup for intensive medical support. Out of four referred cases, three lost to follow up and one improved. Both the cases that expired and referred were children below 10 years of age.

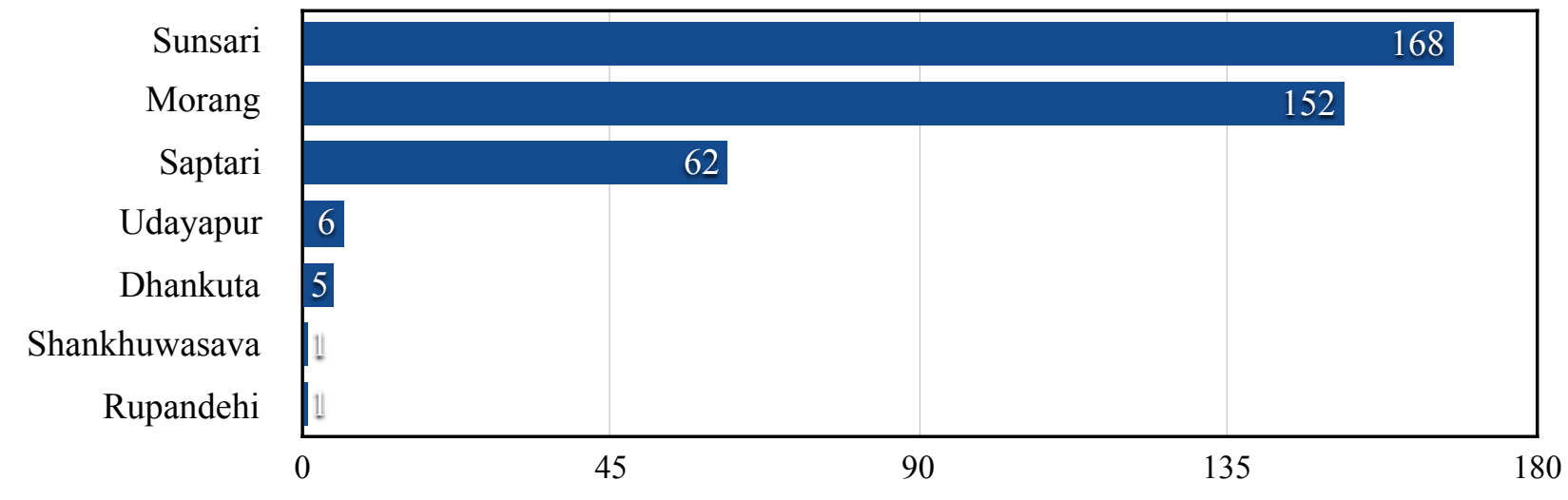

Figure 3: Snake bite cases from different districts of terai region of Nepal. $(n=395)$ 


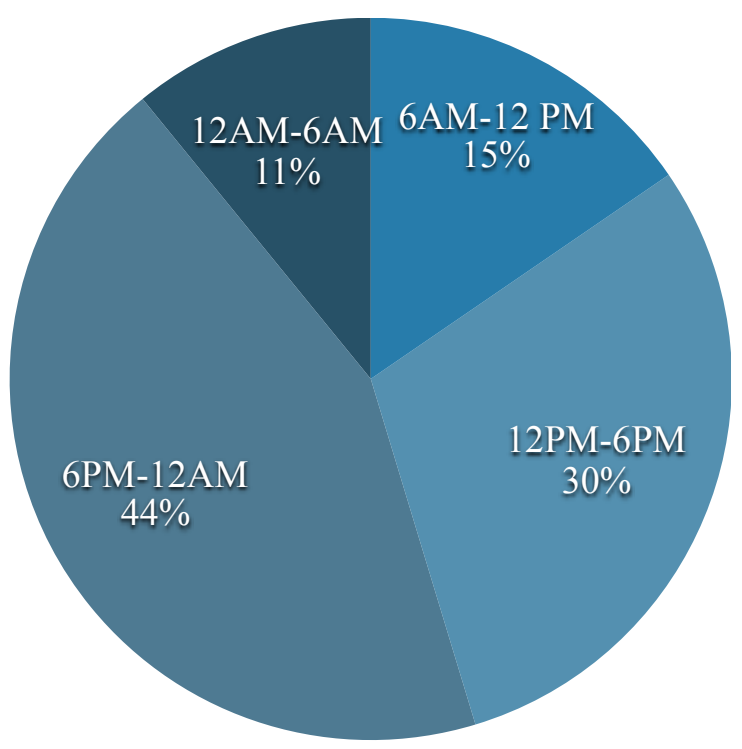

Figure 4: Time of snake bite cases

\section{DISCUSSION}

It has been estimated that more than 20,000 cases of snake-bite with around 1,000 deaths occur yearly in Nepal. ${ }^{2}$ The true existing epidemiological data of snake bite remains scattered and very likely to be underestimated. Hospital records, which are the only reported source of information, projects only tip of the iceberg of snake-bite problems in the community. Though children are more prone to suffer from snake bite due to inquisitiveness and smaller size, there are very few studies on snake bite among the children in Nepal and the published data of prevalence of snake bite among children is unavailable.
Children over 5 years participate mostly in outdoor games whereas children aged 11-18 years in rural communities mostly work in the fields. This makes them susceptible for snake bite as has been found in our study. The result of more number of older children being victims of snake bite was comparable with other studies too. $7,11,12$

Studies had shown that nearly $75 \%$ of snake bites occurred outdoor 13,14 and that boys were affected more than girls. 15 The results of our study are in accordance to other studies done in children. ${ }^{11,16}$ Male preponderance of snake bite can be explained by boys' more engagement in out-door games compared to girls and our traditional practices.

The incidence of snake bite increases in monsoon season when people are engaged in agricultural activities and heavy rain causes flooding. The flood water fills the holes and snakes are forced to be out of their burrows and holes. An increase in human agricultural activities during rainy season also leads to increased exposure between man and snake and favors snake bite. Our study also showed the increased incidence of snake bite during the months of June-July (monsoon season). This wellestablished characteristic pattern had been reported in other studies too. ${ }^{17-19}$

Based on geographical location and climate, increasing prevalence of snake bites are seen in Terai districts of Nepal. In contrast to the result

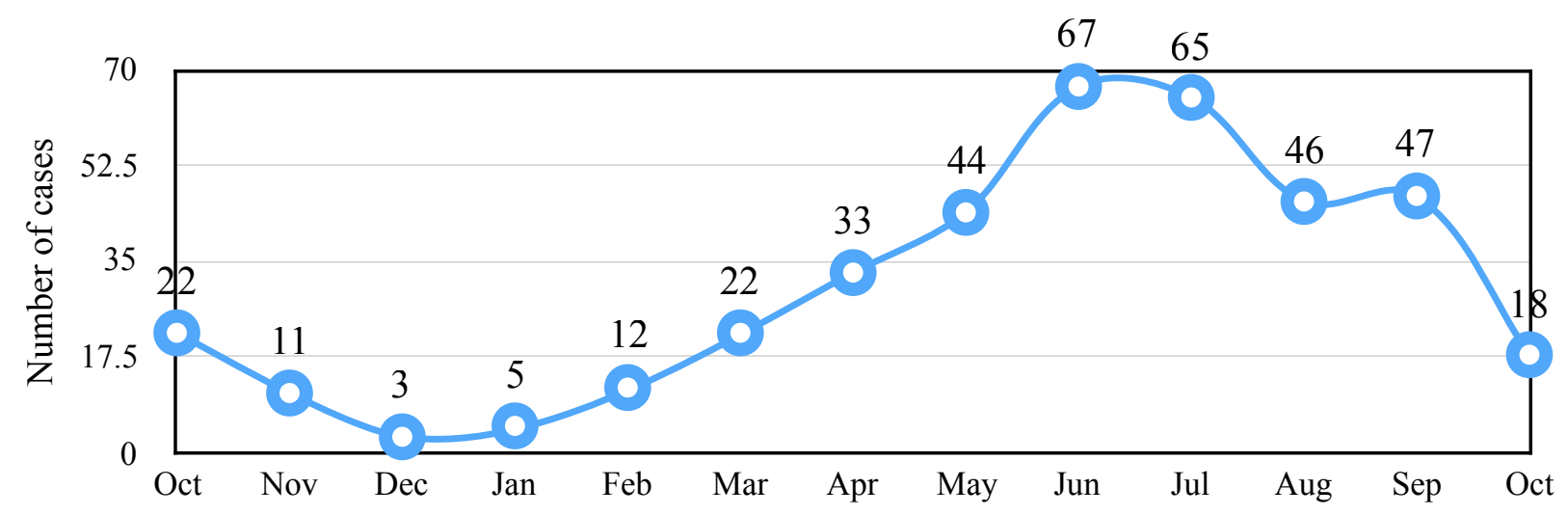

Figure 5: Seasonal variation in number of snake bite cases 
found in study done by Joshi et. al. in

Eastern part of Nepal, our study showed the highest cases of snake bite from Sunsari (42.5\%) followed by Morang (38.5\%) and then Saptari districts (15.7\%). The maximum number of victims from Sunsari district could be explained by the proximity to the location of the snake bite treatment center in Itahari to Sunsari.

Though snake bite occur throughout the day, more than $70 \%$ of the snake bite in our study occurred from 12 noon to midnight corresponding to the time of maximum outdoor activities and during sleep. High occurrence of bite during this period Most of the people were unable to distinguish poisonous and non-poisonous snakes, hence exact data of poisonous snake bite is difficult to be obtained. 3,25 It could be due to difficulty in seeing the snakes during night or due to people's ignorance about the types of snake. In our study also most of the snakes remained unidentified $(88.3 \%)$ as seen in other studies. Hence treatment with ASV was dependent on the clinical features of envenomation rather than the snake identification. ${ }^{12}$ Out of total identified snakes, most common was Cobra bite followed by similar number of Green Pit Viper and Krait bite. This result was in contrast to the result of other studies done in Terai which had shown the most common bite being the Krait. ${ }^{3,} 26$ This could be explained by easy identification of live Cobras by people through their hood formation at minimal provocation. ${ }^{3}$

Our study showed that only $7.1 \%$ snake bites were envenomed and needed treatment with (ASV). This is in harmony with the study done by Devkota U.N. et. al. ${ }^{25}$ Though literatures on adult study have mentioned $40 \%$ of the known poisonous snake bite to be dry bite, our study showed only $25 \%$ of the identified snake bites were dry. ${ }^{24} \mathrm{~A}$ study done in Bangladesh, showed even high percentage (91\%) ofASV treatment requirement in venomous bites, could be due to poor visibility during the night or neglecting the preventive measures of snake bite during sleep as well as going for work. ${ }^{3}$

Lower extremities are most commonly bitten by snake as people step over them accidentally while walking or playing in the dark. ${ }^{19} 68.9 \%$ of patients in our study had bites on lower extremities which is similar to other studies.20-23 Children are very curious in nature and are always exploring the holes and cracks, the most common places for snakes to hide, which results in bites in the upper limbs. ${ }^{24}$ This explains the second leading site of snake bite (29.9\%) as upper limbs in our study. ${ }^{12,25}$ only $9 \%$ being dry bites. ${ }^{27}$ This could be explained by the fact that children having relatively smaller body size will receive larger venom dose per kilogram of body weight during the bite hence, are more vulnerable to severe envenomation. ${ }^{28}$

Cobras and Krait are highly poisonous snakes. Viperids except the Russell's Viper, produce either less toxic venom or insufficient amount of venom to kill human beings. Hence, Viper bites rarely require treatment with $\mathrm{ASV}^{3}$. This can explain our finding, showing most of the bites with Elapidae family were envenomed and needed treatment with ASV, however none of the Viper bite showed clinical features of envenomation. The cases that died or went into complications requiring referral were children below 10 years of age. This could be explained by lesser weight of smaller children in relation to the venom dose injected thus making them more prone for complications ${ }^{28}$.

\section{CONCLUSIONS}

Snake bite is highly prevalent in the Terai region especially during monsoon seasons. Children with high mobility around household or fields are more susceptible to snake bites and also more vulnerable to envenomation requiring ASV treatment as well as complications. Ensuring preventive measures 
against snake bite would be helpful to decrease the prevalence of snake bite in the community.

\section{ACKNOWLEDGEMENT}

Authors would like to express their sincere thanks to the paramedical staffs at the snake bite treatment center, Itahari, Nepal.

\section{RERERENCES}

1. Hansdak S, Lallar K, Pokharel P, Shyangwa P, Karki P, Koirala S. A clinico-epidemiological study of snakebite in Nepal. Trop Doct 1998 Oct;28(4). https://doi.org/10.1177/004947559802800412 PMid:9803844

2. Devkota UN SJ, Shah LN. Snakebite in Nepal, A study from Siraha district. J Nepal Med Assoc. 2000;Vol. 39:203-9.

3. Shah KB, Shrestha JM, Thapa CL. Snake Bite Management Guideline. In: Department of Health Services EaDCDaZCS-S, editor. 1st edAugust 2003. p. 1-32.

4. J-P C. Snake-bites: appraisal of the global situation. Bull World Health Organ 1998.

5. Baseline epidemiological study on snake-bite treatment and management. World Health Organization, 1987.6. Jamaiah I, Rohela M, Roshalina R, Undan R. Prevalence of snake bites in Kangar district hospital, Perlis West Malaysia: a retrospective study (January 1999-December 2000). South East Asian J Trop Med Public Health. 2004;35:962-5. PMid:15916099

7. Vinayak Y. Kshirsagar, Minhajuddin Ahmed, Colaco SM. Clinical Profile of Snake Bite in Children in Rural India. Iran J Pediatr. 2013 Dec;23(6):632-6.

8. Joshi DD, Kawamura Y, Toriba M, Hayashi Y. Epidemiological Surveillance Study of Snakes and Snakebite Human Cases in All Terai Districts of Nepal. Chagal, Kathmandu, Nepal: 2007.

9. Bhetwal B, O'Shea M, Warrell D. Snakes and snake bites in Nepal. Trop Doct 1998;28:193-5. DOI: https://doi.org/10.1177/004947559802800401 PMid:9803834

10. DA W, . Handbook of Clinical Toxicology of Animal Venoms and Poisons. White J, Meier J, editors. Florida: CRC Press; 1995. 433-92

11. Paudel K, Sharma S. Study of Clinico-Epidemiological Profile and Outcome of Poisonous Snake Bites in Children. J Nepal Paediatr Soc 2012;32:47-52.

DOI: https://doi.org/10.3126/jnps.v32i1.5948

12. Koirala D, Gauchan E, Basnet S, Adhikari S, BK G. Clinical Features, Management and Outcome of Snake Bite in Children. Nepal Journal of Medical sciences. July-December 2013; 02(02):19-24

13. Singh S, Singhi S, Sood N. Changing patterns of childhood poisoning (1970-1989)-experience of a large north India hospital. I Pediatr. 1995;32:331-6.

14. Rodriguez J, Sattin R. Epidemiology of childhood poisonings leading to hospitalization in the United States.1979-1983. Am J Prev Med 1987;3:168-71.

15. Gaitonde BB BS. An epidemiological survey of snake-bite cases in India. The Snake. 1980;12:129-33. 
16. BM S. Outcomes of Snakebite Envenomation in Children . J Nepal Paediatr Soc. 2011;31:192-7.

17. Pandey D. Epidemiology of snakebites based on field survey in Chitwan and Nawalparasi districts, Nepal. JMed Toxicol. 2007Dec;3(4):164-8.

DOI: https://doi.org/10.1007/BF03160933 PMid:18072170 PMCid:PMC3550019

18. Currie B, Sutherland S, Hudson B, Smith A. An epidemiological study of snakebite envenomation in Papua New Guinea. Med J Aust. 1991;154(4):266-8.

PMid:1994203

19. Jamieson R, Pearn J. An epidemiological and clinical study of snake-bites in childhood. Med J Aust. 1989;150(12):698-702.

PMid:2733617

20. Punde D. Management of snake-bite in rural Maharashtra: A 10-year experience. Natl Med J India. 2005;18(2):71-5.

PMid:15981441

21. Saborio P, Gonzalez M, Cambronero M. Snakebite accidents in children in Costa Rica: epidemiology and determination of risk factors in the development of abscess and necrosis [Spanish]. Toxicon. 1998;36(2):359-66.

PMid:9620583

22. Bawaskar H, Bawaskar P. Management of snake bite and scorpion sting. Quart Med Rev. 2009;60(4):4.

23. Lovecchio F, DeBus D. Snakebite envenomation in children: a 10-year retrospective review. Wilderness Environ Med. 2001;12(3):184-89.

DOI: https://doi.org/10.1580/1080-6032(2001)012[0184:SEICAY]2.0.CO;2

24. Parrish H, Goldner J, Silberg S. Comparison between snakebite in children and adults. Pediatrics. 1965;36:251-6.

PMid:14320035

25. Devkota UN, Steinmann JP, Kathayat JB. Epidemiology of Snake bite; A study from Choharwa Army Camp, Siraha, Nepal. J Nepal Med Assoc. 2001;40:57-62.

26. Paudel K, Sharma S. Study of Clinico-Epidemiological Profile and Outcome of Poisonous Snake Bites in Children. J Nepal Paediatr Soc 2012;32(47-52).

DOI: https://doi.org/10.3126/jnps.v32i1.5948

27. Hasan S, Basher A, Molla A, Sultana N, Faiz M. The impact of snake bite on house hold economy in Bangladesh. Trop Doct2012. p. 41-3.

DOI: https://doi.org/10.1258/td.2011.110137

28. Otten E. Venomous animal injuries. Emergency Medicine concepts and clinical practices. New York: Mosby; 1998. 